\title{
BMJ Global Health Sociocultural and health system factors associated with mortality among febrile inpatients in Tanzania: a prospective social biopsy cohort study
}

Michael E Snavely, ${ }^{1}$ Michael J Maze, ${ }^{2}$ Charles Muiruri, ${ }^{1}$ Lilian Ngowi, ${ }^{3}$ Flora Mboya, ${ }^{3}$ Julia Beamesderfer, ${ }^{4}$ Glory F Makupa, ${ }^{5}$ Anthon G Mwingwa, ${ }^{5}$ Bingileki F Lwezaula, ${ }^{6}$ Blandina T Mmbaga, ${ }^{3}$ Venance P Maro, ${ }^{5}$ John A Crump, ${ }^{2}$ Jan Ostermann, ${ }^{7}$ Matthew $\mathrm{P}$ Rubach ${ }^{8}$

To cite: Snavely ME, Maze MJ, Muiruri C, et al. Sociocultural and health system factors associated with mortality among febrile inpatients in Tanzania: a prospective social biopsy cohort study. BMJ Glob Health 2018;3:e000507. doi:10.1136/ bmjgh-2017-000507

Handling editor Soumitra Bhuyan

- Additional material is published online only. To view please visit the journal online (http://dx.doi.org/10.1136/ bmjgh-2017-000507)

Received 1 August 2017 Revised 21 December 2017 Accepted 20 January 2018

Check for updates

For numbered affiliations see end of article.

Correspondence to Dr Matthew P Rubach; matthew.rubach@duke.edu

\section{ABSTRACT}

Introduction Communicable diseases are the leading causes of death in Tanzania despite the existence of effective treatment tools. We aimed to assess the sociocultural and health system factors associated with mortality from febrile illness in northern Tanzania. Methods We interviewed febrile inpatients to determine prevalence of barriers in seeking or receiving care and grouped these barriers using the Three Delays model (delays at home, in transport and at healthcare facilities). We assessed 6-week mortality and, after matching on age, gender and severity of illness, measured the association between delays and mortality using conditional logistic regression.

Results We enrolled 475 children, of whom 18 (3.8\%) died, and 260 adults, of whom 34 (13.0\%) died. For children, home delays were not associated with mortality. Among adults, a delay in care-seeking due to not recognising severe symptoms was associated with mortality (OR: 3.01; 95\% Cl 1.24 to 7.32). For transport delays, taking $>1$ hour to reach a facility increased odds of death in children (OR: $3.27 ; 95 \% \mathrm{Cl} 1.11$ to 9.66 ) and adults (OR: 3.03; 95\% $\mathrm{Cl} 1.32$ to 6.99). For health system delays, each additional facility visited was associated with mortality for children (OR: $1.59 ; 95 \% \mathrm{Cl} 1.06$ to 2.38 ) and adults (OR: $2.00 ; 95 \% \mathrm{Cl} 1.17$ to 3.41 ), as was spending $>4$ days between the first facility visit and reaching tertiary care (OR: 4.39; 95\% Cl 1.49 to 12.93).

Conclusion Our findings suggest that delays at home, in transport and in accessing tertiary care are risk factors for mortality from febrile illness in northern Tanzania. Interventions that may reduce mortality include community education regarding severe symptoms, expanding transportation infrastructure and streamlining referrals to tertiary care for the sickest patients.

\section{INTRODUCTION}

Fever is common in low-resource areas, with a 2-week period prevalence as high as $27 \%$. $^{1}$ In Tanzania, common aetiologies among febrile inpatients include bloodstream infections and bacterial zoonoses, ${ }^{2}$ and febrile illnesses are

\section{Key questions}

What is already known about this topic?

- Social autopsy is a retrospective interview tool that has been used successfully to assess sociocultural and health systems barriers to care in febrile illness.

- Social autopsy is limited, however, by its retrospective approach and lack of control group.

What are the new findings?

- Ours is the first study to our knowledge to use the social autopsy framework in a prospective cohort study and to determine which sociocultural and health system factors are associated with mortality.

- We found that delays in care-seeking, delays in transport and spending more time between initial presentation to a health facility and reaching tertiary level care were all associated with an increased odds of mortality.

Recommendations for policy

- Our results suggest that there are social and health system factors associated with mortality from febrile illness, which may help explain why communicable diseases are still the leading causes of death in Tanzania.

- Interventions to improve severe illness recognition in the community, shorten transport times and expedite referrals to tertiary care when necessary may help prevent deaths from febrile illness in northern Tanzania.

still major causes of death ${ }^{34}$ despite the existence of effective treatment tools such as antimicrobials and clinical management guidelines. ${ }^{5}$ As such, sociocultural, behavioural and health system factors ${ }^{6-8}$ may contribute to mortality from infectious diseases.

Social autopsy has been used to describe non-biological contributors to fatal infections, 
Box 1 List of all 15 barriers to care as used in the severe febrile illness social biopsy study, Tanzania, 2015-2016, categorised by home, transport and health system delays according to the Three Delays model.

\section{Home delays \\ - Patient reported delay in seeking care due to thinking illness was not severe but severe symptom was present. \\ - Patient waited $>24$ hours to seek care after onset of severe symptom. ${ }^{*} \dagger$ \\ - Patient treated at home despite severe symptom.}

\section{Transport delays}

- Patient reported a delay due to transport or cost of transport at any point.

- Patient delayed $>1$ hour to reach a facility at any point. $\nmid \neq$

\section{Health system delay}

- Patient did not get referred to a hospital from the first facility after onset of severe symptom.

- Patient did not take themselves to a hospital after onset of severe symptom (ie, did not 'short-circuit' referral).

- Patient did not receive antibiotics at the first peripheral facility after onset of severe symptom.

- Patient reported a barrier at a health facility due to discrimination, language or physical access.

- Patient waited $>1$ hour to receive medication at any point.*

- Patient visited $>2$ facilities. $† \S$

- Patient waited $>1$ hour to be seen by a provider at any point.*

- Patient reported delay due to cost of healthcare.

- Patient did not complete a given treatment due to patient or caregiver decision.

- Patient spent $>4$ days in the healthcare system. †ी

*This threshold was based on a cut-off value used in the social autopsy literature.

†This delay was also analysed as a continuous variable (see Results). ‡Social autopsy literature has used a cut-off of $>2$ hours, but our participants' average transport time was lower and thus a cut-off of 2 hours was not instructive.

§Social autopsy literature has used a cut-off of $>1$ facility, but since our study was hospital based and we were hoping to test whether the WHO Integrated Management of Childhood IIIness and Adult and Adolescent IIIness guidelines of a severe symptom prompting referral to a hospital were being followed, we set our threshold at $>2$ facilities.

IThe threshold of $>4$ days was set post hoc based on our participants' mean number days spent in the healthcare system.

including malaria in Tanzania ${ }^{9}$ and febrile illness and pneumonia in Uganda. ${ }^{10}{ }^{11}$ Administered as a structured interview to family members following a person's death, social autopsy solicits information on healthcare-seeking, sociocultural barriers to care and barriers within the healthcare system. ${ }^{12}{ }^{13}$ Identification of delays through social autopsy can provide evidence to inform interventions. For example, a social autopsy study in Niger found that transport was the main barrier to effective perinatal care, and the government responded by making motorcycle ambulances available for mothers in labour. ${ }^{14}$

Standard retrospective social autopsy is limited by substantial recall ${ }^{15} 16$ and selection ${ }^{17}$ bias. In addition, without non-fatal controls, social autopsy studies have been unable to conclude whether non-biological factors are truly associated with increased odds of mortality. Furthermore, few social autopsy studies have enrolled non-maternal adults. In our study, we adapted social autopsy for a prospective cohort study of febrile inpatients of all ages. Since our tool is used during life, it is best described as a 'social biopsy'. Our objective was to determine the sociocultural barriers, healthcare-seeking behaviour and health system factors that are associated with mortality from febrile illness in northern Tanzania.

\section{METHODS}

\section{Study area and population}

We enrolled participants at two hospitals in Moshi, Tanzania, the administrative capital of the Kilimanjaro Region. Mawenzi Regional Referral Hospital (MRRH) serves as the region's tertiary referral hospital with 300 beds. Kilimanjaro Christian Medical Centre (KCMC) is one of four consultant tertiary hospitals in Tanzania and has 458 beds, serving a catchment population of more than 10 million people, including people served by MRRH.

Study team members screened all patients admitted to paediatric and adult medical wards at MRRH and KCMC from June 2015 to June 2016. Patients were screened as soon as possible and no later than 48 hours after admission. Patients with a history of fever in the past 72 hours; tympanic, rectal or oral temperature of $\geq 38.0^{\circ} \mathrm{C}$ at admission; or axillary temperature of $>37.5^{\circ} \mathrm{C}$ at admission were eligible to participate in the study.

\section{Data collection}

After obtaining informed consent from the patient or guardian, trained clinical officers administered a structured interview in Kiswahili. We designed our questionnaire based on the International Network for the Demographic Evaluation of Populations and Their Health standardised social autopsy tools for child and maternal death $^{12}$ and the Child Health Epidemiology Reference Group social autopsy questionnaire. ${ }^{13}$ Our questionnaire captured information on participant demographics, socioeconomic characteristics and barriers to care. We also asked about the presence of severe symptoms that should prompt immediate referral to a hospital, as defined by the World Health Organization Integrated Management of Childhood Illness (IMCI) and Integrated Management of Adolescent and Adult Illness (IMAI) guidelines. ${ }^{18} 19 \mathrm{We}$ telephoned participants to assess their vital status within 6 weeks of enrolment in the study.

We defined cases as participants who died within 6 weeks of enrolment and controls as those who were alive at the time of follow-up between 3 and 6 weeks after enrolment. Mirroring the age threshold used at MRRH and KCMC, we defined paediatric participants as those under 13 years of age and adults as those 13 years and older. For analysis of IMCI severe symptoms, we defined infants as participants younger than 12 months of age and children as paediatric participants 12 months of age or older. 
7092 patients screened

5937 not eligible (no fever) 122 with fever declined

735 with 3-6 week follow-up data

Analyzed by age group

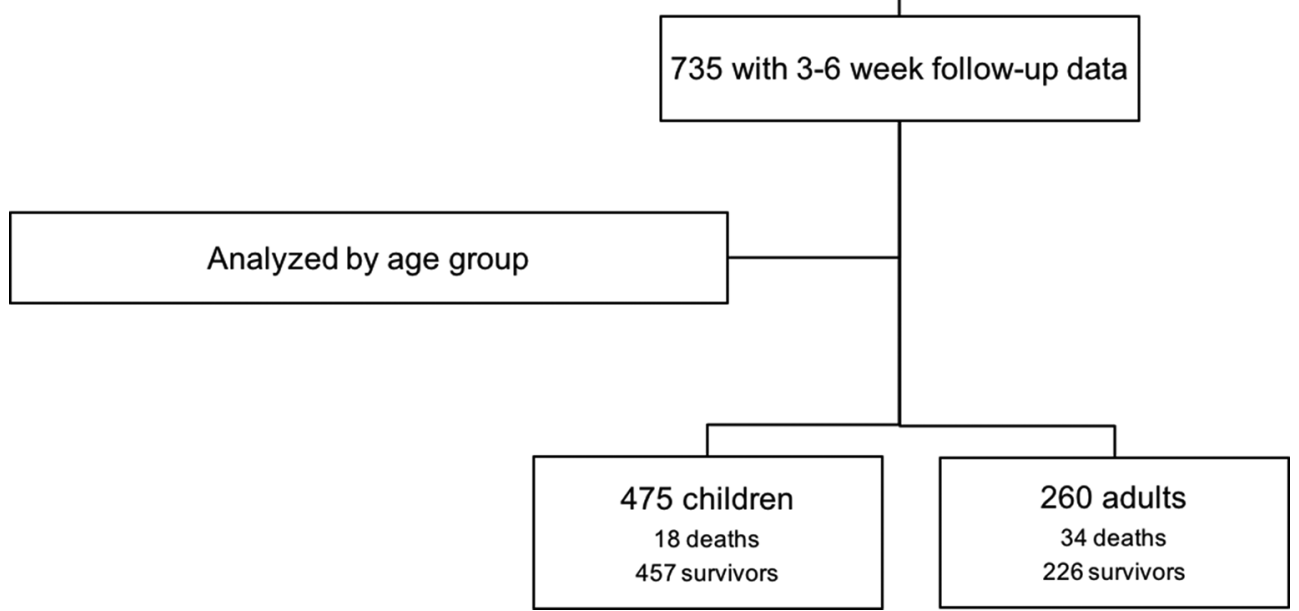

Figure 1 Patients screened, enrolled and reached for follow-up during 1 year of data collection in the severe febrile illness social biopsy study, Tanzania, 2015-2016.

\section{Statistical analysis}

We used a matched case-control analysis nested within our prospective cohort study to measure the association between barriers to care and mortality for paediatric and for adult participants, respectively. We assessed 15 barriers to care, categorised into delays at home, in transport and within the healthcare system based on the Three Delays model (box 1). ${ }^{20}$

Within the paediatric and adult cohorts, respectively, we matched cases with controls based on age quintile, gender and severity of illness. We matched on age quintile to allow for more precise matching on other covariates, and because in estimating outcome from infection, the broader age group is likely an appropriate predictor. ${ }^{21-23}$ When analysing home and transport delays, we matched only on age and gender, as the presence of a severe symptom was implicit in home delays, and transport delays were assessed at multiple points in time and thus did not have reference points at which to measure severity. For healthcare system delays, we matched on age, gender and severity of illness at the time of the first encounter with a healthcare facility during the current illness.

To match on severity of illness, we first determined separately for infants, children and adults whether cases and controls had similar distributions of IMCI or IMAI severe symptoms using the Kolmogorov-Smirnov equality-of-distributions test. If there was a significant difference in distributions, we included a severity of illness score in the matching algorithm. We generated the severity of illness score using principal component analysis of the IMCI or IMAI severe symptoms present at time of study enrolment. Next, we used a logistic regression of mortality with the principal components as explanatory variables to predict a severity of illness score at the time 
of first encounter with a healthcare facility during the current illness.

Our matching algorithm used nearest-neighbour matching with replacement and subsequent deduplication of controls. ${ }^{2425}$ If any cases were left without a matched control, we reassigned controls such that every case was matched with at least one control while maintaining maximum closeness of matching. We then consolidated cases and controls across infants and children to make one paediatric cohort. We measured matching quality using standardised biases and variance ratios of covariates between cases and controls. ${ }^{26} 27$ The ratio of controls to cases was set at a minimum of two but was maximised such that the standardised bias remained below $10.0 \%$ for each covariate. ${ }^{28}$

We measured the association between each delay and 6 -week mortality using conditional logistic regression. We reported results as ORs of mortality with associated population attributable fraction (AF). Statistical analysis was done using Stata V.14.1. We depicted the differences in the sequence and type of facilities visited between cases and controls using an adapted Sankey diagram, generated with 'The Sankey Diagram Generator' (Acquire Procurement Services, Brisbane, Australia). ${ }^{29}{ }^{30}$ We designated private clinics and government-run dispensaries and health centres as first level facilities. We designated district hospitals as secondary level care and regional referral and consultant referral hospitals as tertiary care. ${ }^{31-33}$

To assess the impact of loss to follow-up, we compared baseline characteristics between those lost to follow-up and those included in the analysis using t-tests for means and $\chi^{2}$ tests for proportions. To determine whether a participant's clinical presentation was a confounder, we conducted a sensitivity analysis in which we repeated the conditional logistic regression of mortality for each delay among the subset of participants who had each severe symptom.

\section{Patient involvement}

A pilot period ensured patient feedback was incorporated into the questionnaire design. The results of the study will be made available to patients through dissemination to healthcare providers at MRRH and KCMC.

\section{Research ethics}

Informed consent was obtained from all participants. All authors had full access to relevant study data at all times. The funding sources had no role in the planning, collection or analysis of data. We attest that we have obtained appropriate permissions and paid any required fees for use of copyright protected materials.

\section{RESULTS}

\section{Enrolment}

From 23 June 2015 to 30 June 2016, we screened 7092 inpatient admissions, of whom 1033 (14.6\%) were enrolled (figure 1). Of those enrolled, $647(62.6 \%)$ were paediatric and $386(37.4 \%)$ were adult participants. We administered complete questionnaires and obtained 6-week vital status for 735 (71.2\%) participants, of whom $475(64.6 \%)$ were paediatric and $260(35.4 \%)$ were adult. Eighteen $(3.8 \%)$ paediatric participants and $34(13.1 \%)$ adults died.

\section{Participant characteristics}

Of 475 paediatric participants, the median age was 1.2 (IQR 0.6-2.6) years, 205 (43.2\%) were female and 237 (49.9\%) participant caregivers had not received education beyond primary school (table 1A). Caregivers of four $(0.8 \%)$ participants reported the child being HIV seropositive.

Of 260 adult participants, the median age was 38.4 (IQR 24.1-52.9) years, 119 (45.8\%) were female and 166 $(63.8 \%)$ had not received education beyond primary school (table 1B). Sixty-nine $(26.5 \%)$ adults were farmers by occupation and $42(16.2 \%)$ reported being HIV seropositive.

\section{Matched analysis}

Both infant and children groups had no differences between cases and controls in the distributions of severe symptoms $(\mathrm{P}=0.960$ and $\mathrm{P}=0.980$, respectively). Thus, matching by severity of illness was not required (online supplementary table 1 ). For adults, there was a difference in severe symptom distributions between cases and controls $(\mathrm{P}=0.004)$, and thus adult participants were matched on age, gender and, for the analysis of health system delays, severity of illness.

\section{Three delays}

Among 475 paediatric participants, 457 (96.2\%) experienced at least 1 of 15 total delays, and the median number of delays per participant was 3 (IQR 2-5). Each additional delay present during a paediatric illness was associated with increased odds of death (OR: 1.28; 95\% CI 1.03 to 1.59 ). For adult participants, the median number of delays per participant was 3 (IQR 2-5), and $248(95.4 \%)$ of 260 participants experienced at least one delay.

\section{Delays at home}

Among paediatric participants, the associations between delays at home and mortality were not statistically significant (table 2). Among adults, a delay in care-seeking due to not recognising a severe symptom was associated with mortality (OR: $3.01 ; 95 \%$ CI 1.24 to 7.32 ; AF: $23.6 \%$; $95 \%$ CI $12.4 \%$ to $33.3 \%$ ). Waiting $>24$ hours to seek care after the onset of a severe symptom was also associated with increased odds of mortality (OR: 2.50; 95\% CI 1.11 to 5.63 ; AF: $34.5 \%$; $95 \%$ CI $12.8 \%$ to $50.8 \%$ ). Analysed as a continuous variable, each additional day between the onset of a severe symptom and the first attempt to seek care was associated with mortality (OR: $1.21 ; 95 \%$ CI 1.01 to 1.46). Of the three home delays (box 1), each additional delay present had an OR of 1.73 (95\% CI 1.10 to 2.71) for mortality. 
Table 1A Background characteristics and prevalence of severe symptoms for 475 paediatric participants in the severe febrile illness social biopsy study, Tanzania, 2015-2016.

\begin{tabular}{|c|c|c|c|c|c|c|}
\hline \multirow[b]{2}{*}{ Characteristic } & \multirow[b]{2}{*}{ Total $(n=475)$} & \multirow[b]{2}{*}{ Cases $(n=18)$} & \multirow{2}{*}{$\begin{array}{l}\text { Survivors } \\
(\mathrm{n}=457)\end{array}$} & \multirow[b]{2}{*}{$\mathrm{P}$ value } & \multicolumn{2}{|c|}{ Matched on age and gender } \\
\hline & & & & & Controls $(n=142)$ & P value \\
\hline Age (years) & $2.2(2.5) \S$ & $1.8(2.2) \S$ & $2.2(2.5) \S$ & 0.524 & $1.9(2.2) \S$ & 0.791 \\
\hline $\begin{array}{l}\text { Duration of illness at time of } \\
\text { enrolment (days) }\end{array}$ & $6.6(5.2) \S$ & $12.4(13.0) \S$ & $6.4(4.5) \S$ & $<0.001$ & $6.6(5.1) \S$ & $<0.001$ \\
\hline \multicolumn{7}{|l|}{ Gender } \\
\hline Female & $205(43.2)$ & $10(55.6)$ & $195(42.7)$ & 0.283 & $75(52.8)$ & 0.826 \\
\hline \multicolumn{7}{|l|}{ Admitting hospital } \\
\hline $\mathrm{KCMC}$ & $251(52.8)$ & $13(72.2)$ & $238(52.1)$ & & 77 (54.2) & \\
\hline MRRH & $224(47.2)$ & $5(27.8)$ & $219(47.9)$ & 0.093 & $65(45.8)$ & 0.147 \\
\hline \multicolumn{7}{|l|}{ Tribe } \\
\hline Chagga & $232(48.8)$ & $6(33.3)$ & $226(49.5)$ & & $57(40.1)$ & \\
\hline Pare & $61(12.8)$ & $5(27.8)$ & $56(12.3)$ & & $24(16.9)$ & \\
\hline Maasai & $16(3.4)$ & $0(0.0)$ & $16(3.5)$ & & $5(3.5)$ & \\
\hline Other & $166(34.9)$ & $7(38.9)$ & $159(34.8)$ & 0.180 & $56(39.4)$ & 0.601 \\
\hline \multicolumn{7}{|l|}{ Educationף } \\
\hline None & $11(2.3)$ & $1(5.6)$ & $10(2.2)$ & & $4(2.8)$ & \\
\hline Primary (1-7 years) & $226(47.8)$ & $10(55.6)$ & $216(47.5)$ & & $65(46.1)$ & \\
\hline Secondary (8-11 years) & $152(32.1)$ & $6(33.3)$ & $146(32.1)$ & & $53(37.6)$ & \\
\hline High school (12-13years) & $2(0.4)$ & $0(0.0)$ & $2(0.4)$ & & $0(0.0)$ & \\
\hline University/college & $82(17.3)$ & $1(5.6)$ & $81(17.8)$ & 0.616 & $19(13.5)$ & 0.670 \\
\hline \multicolumn{7}{|l|}{ Home region } \\
\hline Kilimanjaro & $427(90.1)$ & $14(77.8)$ & $413(90.6)$ & & $130(91.5)$ & \\
\hline Other & $47(9.9)$ & $4(22.2)$ & $43(9.4)$ & 0.075 & $12(8.5)$ & 0.067 \\
\hline \multicolumn{7}{|l|}{ Urban status ${ }^{\star \star}$} \\
\hline Urban & $258(64.7)$ & $6(46.2)$ & $252(65.3)$ & & $84(69.4)$ & \\
\hline Mixed & $22(5.5)$ & $1(7.7)$ & $21(5.4)$ & & $5(4.1)$ & \\
\hline Rural & $119(29.8)$ & $6(46.2)$ & $113(29.3)$ & 0.363 & $32(26.4)$ & 0.236 \\
\hline \multicolumn{7}{|l|}{ Self-reported HIV status } \\
\hline Positive & $4(0.8)$ & $0(0.0)$ & $4(0.9)$ & 0.690 & $142(100.0)$ & 1.000 \\
\hline \multicolumn{7}{|c|}{$\begin{array}{l}\text { Recent hospitalisation (previous } \\
12 \text { months) }\end{array}$} \\
\hline Yes & $174(36.6)$ & $10(55.6)$ & $164(35.9)$ & 0.089 & $46(32.4)$ & 0.052 \\
\hline \multicolumn{7}{|l|}{ Has health insurance } \\
\hline Yes & $89(18.7)$ & $1(5.6)$ & 88 (19.3) & 0.144 & $28(19.7)$ & 0.142 \\
\hline \multicolumn{7}{|l|}{$\begin{array}{l}\text { Severe symptoms on entering } \\
\text { health system }\end{array}$} \\
\hline Lethargy & $87(18.3)$ & $5(27.8)$ & $82(17.9)$ & 0.290 & $26(18.3)$ & 0.338 \\
\hline Inability to drink & $48(10.1)$ & $4(22.2)$ & $44(9.6)$ & 0.082 & $17(12)$ & 0.225 \\
\hline Convulsions & 79 (16.6) & $6(33.3)$ & $73(16)$ & 0.052 & $23(16.2)$ & 0.075 \\
\hline Vomiting & $244(51.5)$ & $10(55.6)$ & $234(51.3)$ & 0.724 & 68 (47.9) & 0.540 \\
\hline Stiff neck & $12(2.5)$ & $0(0)$ & $12(2.6)$ & 0.486 & $3(2.1)$ & 0.534 \\
\hline Severe skin pustules†† & $10(4.9)$ & $0(0)$ & $10(5.1)$ & 0.487 & $4(6.1)$ & 0.448 \\
\hline Less movement†† & $185(89.8)$ & $9(100)$ & $176(89.3)$ & 0.301 & $61(92.4)$ & 0.393 \\
\hline Chest indrawing†† & 35 (17.2) & $5(55.6)$ & $30(15.4)$ & 0.002 & $11(16.7)$ & 0.008 \\
\hline Pus draining from eart† & $1(0.5)$ & $0(0)$ & $1(0.5)$ & 0.830 & $1(1.5)$ & 0.710 \\
\hline
\end{tabular}


Table 1A Continued

\begin{tabular}{|c|c|c|c|c|c|c|}
\hline \multirow[b]{2}{*}{ Characteristic } & \multirow[b]{2}{*}{ Total $(n=475)$} & \multirow[b]{2}{*}{ Cases $(n=18)$} & \multirow{2}{*}{$\begin{array}{l}\text { Survivors } \\
(\mathrm{n}=457)\end{array}$} & \multirow[b]{2}{*}{$P$ valuet } & \multicolumn{2}{|c|}{ Matched on age and gender* } \\
\hline & & & & & Controls (n=142) & $P$ value $\ddagger$ \\
\hline Nasal flaring†† & $26(12.7)$ & $1(11.1)$ & $25(12.8)$ & 0.885 & $10(15.2)$ & 0.748 \\
\hline Grunting†† & 25 (12.2) & $1(11.1)$ & $24(12.2)$ & 0.919 & $8(12.1)$ & 0.930 \\
\hline
\end{tabular}

Data are reported as $\mathrm{n}(\%)$ unless otherwise indicated.

*9:1 nearest-neighbour matching with deduplication.

†P value is for the differences between cases and all survivors. $\mathrm{P}$ values are derived from t-test for means and $\chi^{2}$ tests for proportions.

$\ddagger \mathrm{P}$ value is for the differences between cases and the given set of matched controls. $\mathrm{P}$ values are derived from $\mathrm{t}$-test for means and $\chi^{2}$ tests

for proportions.

§Data are reported as mean (SD).

"Highest education level completed by the caregiver.

**Urban, mixed or rural were assigned at ward level and are based on classification from the 2012 census that defined urban as, 'localities

that are identified as urban areas by the district authority'. Mixed refers to wards containing both urban and rural villages.

††Only assessed for participants less than 1 year of age.

KCMC, Kilimanjaro Christian Medical Centre; MRRH, Mawenzi Regional Referral Hospital.

\section{Transport delays}

For paediatric participants, taking $>1$ hour to reach a healthcare facility at any point was associated with increased odds of death (OR: 3.27; 95\% CI 1.11 to 9.66; AF: $27.0 \%$; $95 \%$ CI $12.9 \%$ to $38.8 \%$; table 3 ). Of the two transport delays (box 1), each additional delay present was associated with mortality (OR: $2.45 ; 95 \%$ CI 1.12 to 5.33). Among adults, taking $>1$ hour to reach a facility at any point had an OR of 3.03 (95\% CI 1.32 to 6.99; AF: $25.6 \%$; $95 \%$ CI $14.3 \%$ to $35.5 \%$ ) for mortality, and each additional transport delay was associated with 2.16 increased odds of death (95\% CI 1.07 to 4.36).

\section{Healthcare system delays}

Among paediatric participants, each additional healthcare facility visited was associated with increased mortality (OR: 1.59; 95\% CI 1.06 to 2.38; table 4). Participants spending $>4$ days between the first presentation to a healthcare facility and reaching tertiary care had increased odds of mortality (OR: 4.39; 95\% CI 1.49 to 12.93; $\mathrm{AF} 42.9 \%$; $95 \%$ CI $27.4 \%$ to $55.1 \%$ ). Analysed as a continuous variable, the number of days between the first presentation to a healthcare facility and reaching tertiary care was also associated with mortality (OR: $1.09 ; 95 \%$ CI 1.02 to 1.17 ) per unit time in days.

Among adult participants, visiting $>2$ healthcare facilities was associated with mortality (OR: 5.33 ; 95\% CI 1.46 to 19.41 ; $\mathrm{AF}$ : $34.5 \%$; $95 \%$ CI $18.4 \%$ to $47.4 \%$; table 4 ), as was spending $>4$ days between the first presentation to a healthcare facility and reaching tertiary care (OR: 3.15; 95\% CI 1.11 to 8.92 ; AF: $32.1 \%$; $95 \%$ CI $14.7 \%$ to $46.0 \%$ ). Analysed as a continuous variable, each additional healthcare facility visit was associated with 2.00 increased odds of death (95\% CI 1.17 to 3.41 ).

\section{Healthcare system pathway}

Among paediatric participants, both cases and controls visited up to four healthcare facilities (figure 2A). Participants not visiting a tertiary level facility within their first two facility visits had greater odds of death than those who did (OR: 2.88; 95\% CI 1.01 to 8.20). Among adult participants, cases visited up to six healthcare facilities, whereas no controls visited $>3$ facilities (figure 2B). Not reaching tertiary level care within the first two facility visits was also associated with increased odds of mortality among adults (OR: 5.24; 95\% CI 1.47 to 18.69 ).

\section{Sensitivity analysis}

Among paediatric participants, 103 (59.5\%) of those who were lost to follow-up had a caregiver with no more than primary school education, compared with $226(47.8 \%)$ of those in the study cohort $(\mathrm{P}<0.001$; online supplementary table 2A). Of those paediatric participants lost to follow-up, five $(2.9 \%)$ participants reported the child being HIV seropositive compared with four $(0.8 \%)$ of those in the study cohort $(\mathrm{P}=0.049)$. Forty-four $(25.4 \%)$ of the paediatric participants lost to follow-up had one or more prior hospitalisations in the previous 12 months, compared with $174(36.6 \%)$ of those in the study cohort $(\mathrm{P}=0.008)$ and $16(9.2 \%)$ of those lost to follow-up reported having health insurance, compared with 89 $(18.7 \%)$ of those in the study cohort $(\mathrm{P}=0.004)$.

Among adult participants, $8(6.3 \%)$ of those lost to follow reported having a chronic comorbidity, compared with $46(17.7 \%)$ of those in the study cohort $(\mathrm{P}=0.003$; online supplementary table $2 \mathrm{~B}$ ).

In a sensitivity analysis of symptom-specific associations between delays and mortality, there were no significant associations between delays and mortality among paediatric or adult participants for any of the severe symptom subsets (online supplementary table $3 \mathrm{~A}$ and $\mathrm{B}$ ).

\section{DISCUSSION}

We found that for patients admitted with febrile illness in northern Tanzania, delays at home, in transport and in the healthcare system were common. After controlling for age, gender and severity of illness, death was associated with delayed care-seeking and a lack of recognition of severe illness by adult participants or their caregivers. 
Table 1B Background characteristics and prevalence of severe symptoms for 260 adult participants in the severe febrile illness social biopsy study, Tanzania, 2015-2016.

\begin{tabular}{|c|c|c|c|c|c|c|c|c|}
\hline \multirow[b]{2}{*}{ Characteristic } & \multirow[b]{2}{*}{ Total $(n=260)$} & \multirow[b]{2}{*}{ Cases $(n=34)$} & \multirow[b]{2}{*}{$\begin{array}{l}\text { Survivors } \\
(\mathrm{n}=226)\end{array}$} & \multirow[b]{2}{*}{$P$ value } & \multicolumn{2}{|c|}{$\begin{array}{l}\text { Matched on age and } \\
\text { gender* }\end{array}$} & \multicolumn{2}{|c|}{$\begin{array}{l}\text { Matched on age, } \\
\text { gender and severity of } \\
\text { illnesst }\end{array}$} \\
\hline & & & & & $\begin{array}{l}\text { Controls } \\
(n=122)\end{array}$ & $\mathrm{P}$ value§ & $\begin{array}{l}\text { Controls } \\
(n=47)\end{array}$ & $P$ value§ \\
\hline Age (years) & 40.3 (17.9)ๆ & 47.6 (20.4)介 & $39.2(17.2) \uparrow$ & 0.011 & 44.5 (18.2)ๆ & 0.402 & 43.1 (18.6)ף & 0.306 \\
\hline $\begin{array}{l}\text { Duration of illness at } \\
\text { time of enrolment (days) }\end{array}$ & $9.6(10.4) \Re$ & 15.1 (16.0)ף & $8.8(9.0) \emptyset$ & 0.001 & 8.2 (7.8)ף & 0.001 & 9.7 (12.9)ף & 0.103 \\
\hline \multicolumn{9}{|l|}{ Gender } \\
\hline Female & 118 (45.9) & $13(38.2)$ & $105(47.1)$ & 0.335 & $51(41.8)$ & 0.708 & $14(29.8)$ & 0.426 \\
\hline \multicolumn{9}{|l|}{ Admitting hospital } \\
\hline $\mathrm{KCMC}$ & $112(43.1)$ & $22(64.7)$ & 90 (39.8) & & $51(41.8)$ & & $22(46.8)$ & \\
\hline MRRH & 148 (56.9) & $12(35.3)$ & $136(60.2)$ & 0.006 & 71 (58.2) & 0.018 & $25(53.2)$ & 0.111 \\
\hline \multicolumn{9}{|l|}{ Tribe } \\
\hline Chagga & 136 (52.3) & $17(50)$ & 119 (52.7) & & 71 (58.2) & & 23 (48.9) & \\
\hline Pare & $41(15.8)$ & $7(20.6)$ & $34(15.0)$ & & 15 (12.3) & & $7(14.9)$ & \\
\hline Maasai & $4(1.5)$ & $0(0.0)$ & $4(1.8)$ & & $2(1.6)$ & & $1(2.1)$ & \\
\hline Other & 79 (30.4) & $10(29.4)$ & $69(30.5)$ & 0.746 & 34 (27.9) & 0.533 & $16(34)$ & 0.746 \\
\hline \multicolumn{9}{|l|}{ Education ${ }^{\star *}$} \\
\hline None & $7(2.7)$ & $1(2.9)$ & $6(2.7)$ & & $3(2.5)$ & & $1(2.1)$ & \\
\hline Primary (1-7years) & $159(61.2)$ & $23(67.6)$ & $136(60.2)$ & & $82(67.2)$ & & $29(61.7)$ & \\
\hline $\begin{array}{l}\text { Secondary (8- } \\
11 \text { years) }\end{array}$ & 57 (21.9) & $9(26.5)$ & 48 (21.2) & & $18(14.8)$ & & $9(19.1)$ & \\
\hline $\begin{array}{l}\text { High school (12- } \\
\text { 13years) }\end{array}$ & $6(2.3)$ & $0(0.0)$ & $6(2.7)$ & & $4(3.3)$ & & $3(6.4)$ & \\
\hline University/college & 31 (11.9) & $1(2.9)$ & 30 (13.3) & 0.380 & 15 (12.3) & 0.238 & $5(10.6)$ & 0.356 \\
\hline \multicolumn{9}{|l|}{ Home region } \\
\hline Kilimanjaro & 217 (83.5) & $25(73.5)$ & $192(85.0)$ & & $110(90.2)$ & & $40(85.1)$ & \\
\hline Other & $43(16.5)$ & $9(26.5)$ & $34(15.0)$ & 0.095 & $12(9.8)$ & 0.012 & $7(14.9)$ & 0.197 \\
\hline \multicolumn{9}{|l|}{ Urban status $† \dagger$} \\
\hline Urban & $104(54.7)$ & $6(35.3)$ & 98 (56.6) & & $55(56.7)$ & & $21(60.0)$ & \\
\hline Mixed & $6(3.2)$ & $1(5.9)$ & $5(2.9)$ & & $1(1.0)$ & & $0(0.0)$ & \\
\hline Rural & $80(42.1)$ & $10(58.8)$ & $70(40.5)$ & 0.227 & $41(42.3)$ & 0.131 & $14(40.0)$ & 0.118 \\
\hline \multicolumn{9}{|l|}{ Self-reported HIV status } \\
\hline Positive & $42(16.2)$ & $6(17.6)$ & $36(15.9)$ & 0.800 & $20(16.4)$ & 0.862 & $7(14.9)$ & 0.739 \\
\hline \multicolumn{9}{|l|}{$\begin{array}{l}\text { Recent hospitalisation } \\
\text { (previous } 12 \text { months) }\end{array}$} \\
\hline Yes & $72(27.7)$ & $9(26.5)$ & 63 (27.9) & 0.864 & $35(28.7)$ & 0.799 & $13(27.7)$ & 0.905 \\
\hline \multicolumn{9}{|l|}{ Has health insurance } \\
\hline Yes & 61 (23.6) & $6(17.6)$ & 55 (24.4) & 0.384 & 31 (25.6) & 0.335 & $13(27.7)$ & 0.294 \\
\hline \multicolumn{9}{|l|}{ Marital status } \\
\hline Married & $160(62.3)$ & $23(67.6)$ & $137(61.4)$ & 0.486 & 88 (72.7) & 0.562 & $30(65.2)$ & 0.820 \\
\hline \multicolumn{9}{|l|}{ Occupation } \\
\hline Farmer & $69(26.5)$ & $12(35.3)$ & $57(25.2)$ & & $35(28.7)$ & & $16(34.0)$ & \\
\hline Student & 37 (14.2) & $5(14.7)$ & $32(14.2)$ & & $16(13.1)$ & & $8(17.0)$ & \\
\hline Merchant & $43(16.5)$ & $2(5.9)$ & $41(18.1)$ & & $21(17.2)$ & & $4(8.5)$ & \\
\hline Labourer & $37(14.2)$ & $6(17.6)$ & $31(13.7)$ & 0.521 & 15 (12.3) & 0.644 & $4(8.5)$ & 0.833 \\
\hline
\end{tabular}




\begin{tabular}{|c|c|c|c|c|c|c|c|c|}
\hline \multirow[b]{2}{*}{ Characteristic } & \multirow[b]{2}{*}{ Total $(n=260)$} & \multirow[b]{2}{*}{ Cases $(n=34)$} & \multirow[b]{2}{*}{$\begin{array}{l}\text { Survivors } \\
(n=226)\end{array}$} & \multirow[b]{2}{*}{$P$ value $\neq$} & \multicolumn{2}{|c|}{$\begin{array}{l}\text { Matched on age and } \\
\text { gender* }\end{array}$} & \multicolumn{2}{|c|}{$\begin{array}{l}\text { Matched on age, } \\
\text { gender and severity of } \\
\text { illness } †\end{array}$} \\
\hline & & & & & $\begin{array}{l}\text { Controls } \\
(n=122)\end{array}$ & P value§ & $\begin{array}{l}\text { Controls } \\
(n=47)\end{array}$ & P value§ \\
\hline \multicolumn{9}{|l|}{$\begin{array}{l}\text { Has chronic } \\
\text { comorbidity }\end{array}$} \\
\hline Yes & $46(17.7)$ & 7 (20.6) & 39 (17.3) & 0.635 & $26(21.3)$ & 0.927 & $7(14.9)$ & 0.504 \\
\hline \multicolumn{9}{|l|}{$\begin{array}{l}\text { Severe symptoms } \\
\text { present on entering the } \\
\text { health system }\end{array}$} \\
\hline Weakness & $55(21.2)$ & $18(52.9)$ & $37(16.4)$ & $<0.001$ & $11(9)$ & $<0.001$ & $19(40.4)$ & 0.264 \\
\hline Difficulty breathing & $43(16.5)$ & 9 (26.5) & 34 (15) & 0.095 & $7(5.7)$ & 0.026 & $12(25.5)$ & 0.924 \\
\hline Confusion & $11(4.2)$ & $5(14.7)$ & $6(2.7)$ & 0.001 & $3(2.5)$ & 0.316 & $3(6.4)$ & 0.215 \\
\hline Lethargy & $23(8.8)$ & $11(32.4)$ & $12(5.3)$ & $<0.001$ & $4(3.3)$ & $<0.001$ & 7 (14.9) & 0.062 \\
\hline Inability to drink & $13(5)$ & $5(14.7)$ & $8(3.5)$ & 0.005 & $3(2.5)$ & 0.316 & $4(8.5)$ & 0.381 \\
\hline Convulsions & $2(0.8)$ & $0(0)$ & $2(0.9)$ & 0.582 & $2(1.6)$ & 0.452 & $1(2.1)$ & 0.392 \\
\hline Stiff neck & $9(3.5)$ & $2(5.9)$ & $7(3.1)$ & 0.408 & $1(0.8)$ & 0.057 & $2(4.3)$ & 0.739 \\
\hline Abdominal pain & $64(24.6)$ & $8(23.5)$ & $56(24.8)$ & 0.875 & $19(15.6)$ & 0.771 & 7 (14.9) & 0.323 \\
\hline
\end{tabular}

Data are reported as $\mathrm{n}(\%)$ unless otherwise indicated.

*6:1 nearest-neighbour matching with deduplication.

†:1 nearest-neighbour matching with deduplication.

$\ddagger \mathrm{P}$ value is for the differences between cases and all survivors. $\mathrm{P}$ values are derived from t-test for means and $\chi^{2}$ tests for proportions.

$\S \mathrm{P}$ value is for the differences between cases and the given set of matched controls. $\mathrm{P}$ values are derived from $\mathrm{t}$-test for means and $\chi^{2}$ tests for proportions.

"Data are reported as mean (SD).

**Highest education level completed by the patient.

††Urban, mixed or rural were assigned at ward level and are based on classification from the 2012 census that defined urban as, 'localities that are identified as urban areas by the district authority'. Mixed refers to wards containing both urban and rural villages. KCMC, Kilimanjaro Christian Medical Centre; MRRH, Mawenzi Regional Referral Hospital.

Mortality was also higher among paediatric and adult participants who experienced delays in transport and delays in reaching tertiary level care. Presenting to multiple lower-level healthcare facilities was associated with increased odds of death and may be one reason for delayed presentations to tertiary-level care. The findings in this 'social biopsy' study suggest that community education regarding severe symptom recognition, improved transport infrastructure and ensuring rapid referrals to tertiary level facilities may help prevent deaths from febrile illnesses.

Delays at home were associated with increased odds of mortality among adult but not paediatric participants. The distinction between the effects of paediatric and adult delays is important for two reasons. First, social autopsy studies have reported the importance of delays at home among fatal paediatric illness. A study in Uganda found that $42 \%$ of 174 fatal childhood illnesses had delayed seeking care for $>24$ hours after the onset of a severe symptom. ${ }^{12}$ In Ghana, it was shown that $50 \%$ of 264 severe childhood illness were not recognised as severe. ${ }^{34}$ However, we have demonstrated that delays at home were common in both fatal and non-fatal paediatric febrile illnesses, yet they did not increase the odds of death and thus may not be the most important targets for intervention. Second, social autopsy studies have not focused on non-maternal adults. We found that delayed care-seeking due to a lack of severe illness recognition is associated with mortality among adults. This association suggests that $>30 \%$ of febrile deaths among working-age adults might be prevented through education about the severe symptoms that should prompt care-seeking.

We found that a delay $>1$ hour in reaching a facility at any point during an illness increased the odds of mortality among paediatric and adult participants. Several social autopsy studies have found transport delays to be common. ${ }^{12} 14$ 35-37 However, these studies only considered transport delays to the first or last facility. When we limited our analysis to the first or last facility, the association between $>1$ hour delay and mortality was not significant. We also found that each additional transport delay was associated with increased odds of death. Thus, the association of transport delays with mortality was additive and delays in transport to facilities between the first and last were associated with mortality. An initial intervention may be to strengthen referral transportation infrastructure, which could be followed by community ambulance services, which currently are unavailable 

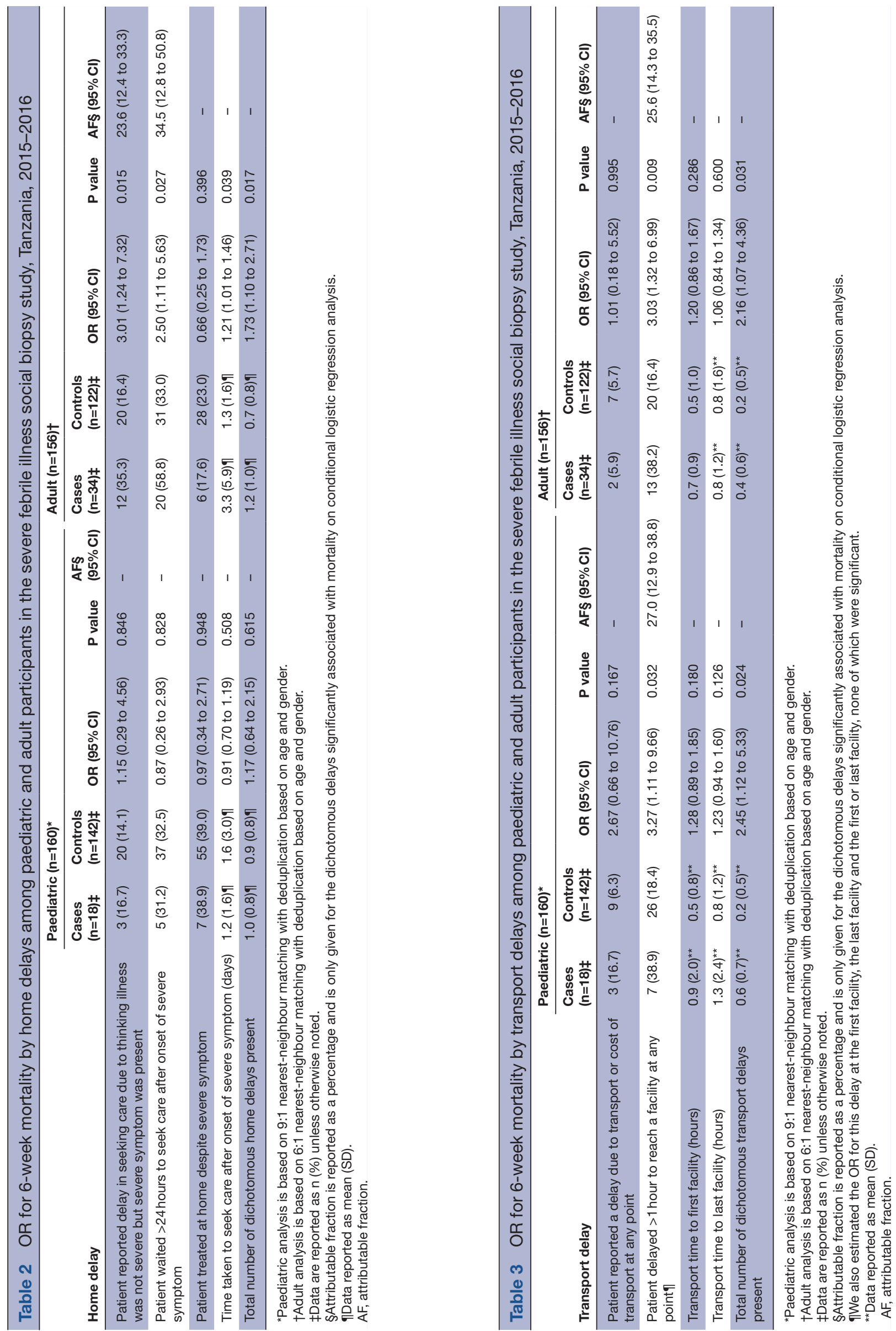


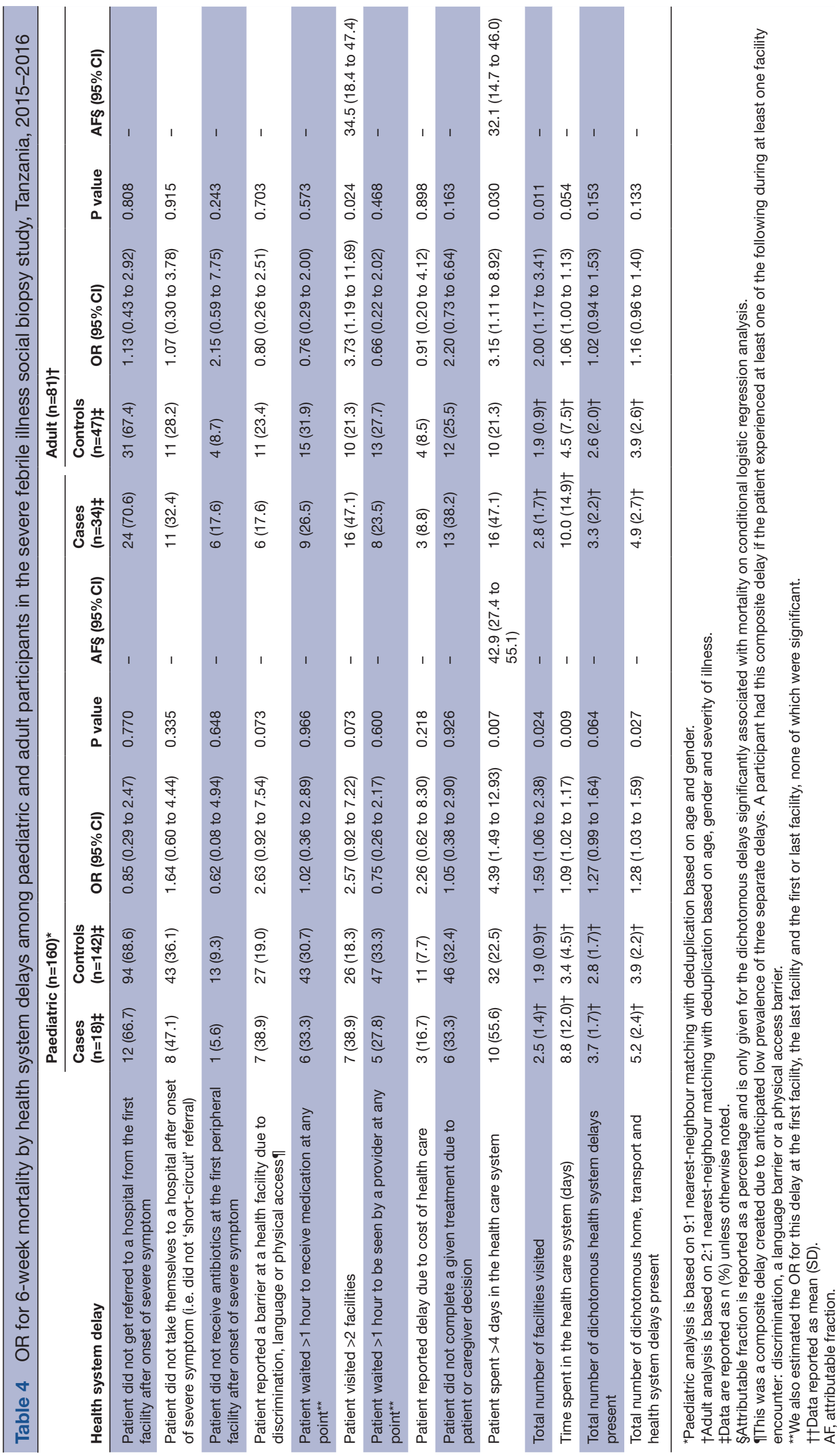



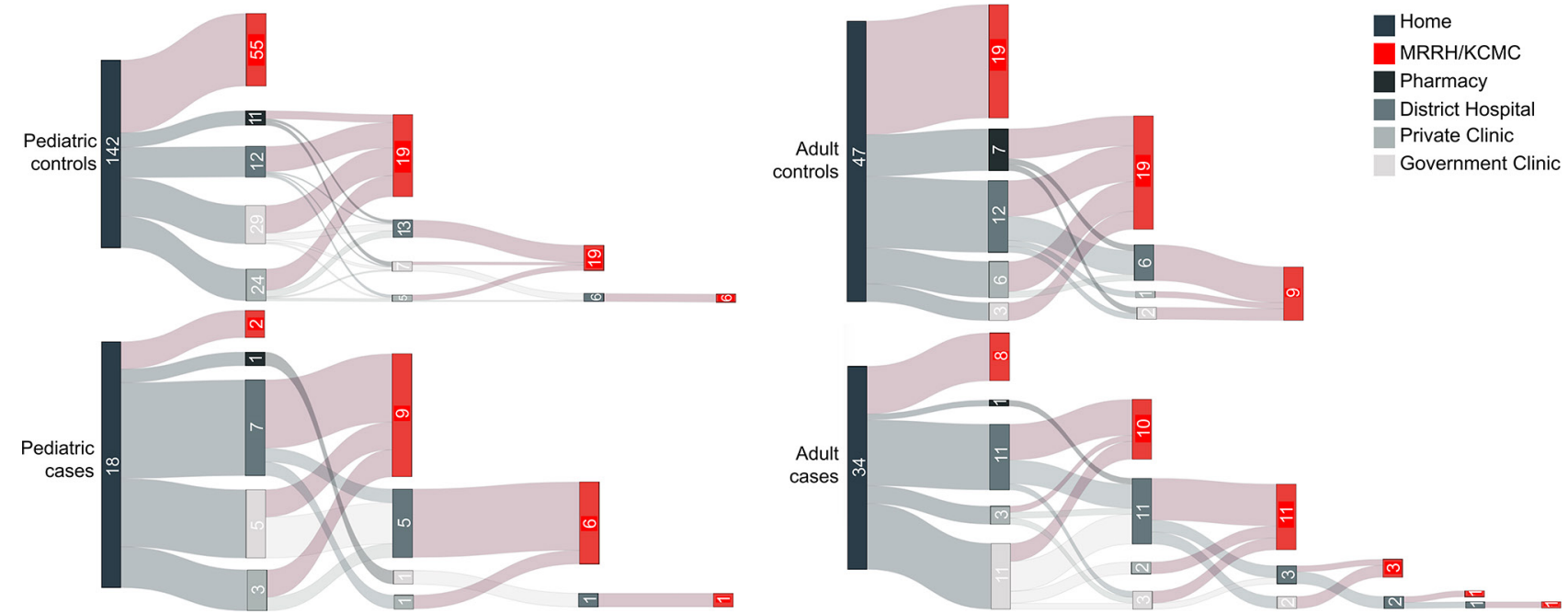

Figure 2 Pathway analysis comparing the pathways through the healthcare system between paediatric and adult cases and matched controls in the severe febrile illness social biopsy study, Tanzania, 2015-2016. Note: from left to right, the diagram depicts each subsequent healthcare facility encounter, such that participants who visited a higher number of facilities have pathways that extend further to the right. The numbers on each node represent the number of participants presenting to that facility and the proportion of total patients traveling to each facility type is reflected in the width of bars flowing from one facility to the next. An individual's pathway ends when he or she reaches MRRH or KCMC represented by the red segments. Matching on severity of illness was done at the time of visiting the first facility, such that cases and controls are equally sick in column 1 of the diagram. MRRH and KCMC were combined in the pathway diagram, as they both provide tertiary-level referral care and they represent the end of participants' healthcare system pathways at the time of enrolment. MRRH, Mawenzi Regional Referral Hospital; KCMC, Kilimanjaro Christian Medical Centre.

in northern Tanzania and have been associated with decreased mortality in other settings. ${ }^{38-40}$

By enrolling at the tertiary hospital level, our study was well suited to examine health system delays, which previous studies have often neglected in favour of analysing patient decision-making delays. ${ }^{41}$ We found that spending $>4$ days between the first facility presentation and reaching tertiary care had an increased odds of mortality for both adult and paediatric participants. In fact, $42.9 \%$ of paediatric and $32.1 \%$ of adult febrile deaths may be attributable to taking $>4$ days to reach tertiary care. Furthermore, each additional facility visit increased the odds of death. A social autopsy study on fatal childhood pneumonia in Uganda showed that only $22 \%$ of patients initially taken to a clinic were referred to a district hospital and that only $31 \%$ of those who reached a district hospital were referred to tertiary care. ${ }^{11}$ We identified similar delays in reaching referral or higher level care and demonstrated that such delays were associated with increased odds of mortality. Therefore, referring the sickest febrile patients directly to tertiary care may reduce the risk of death associated with febrile illness in Tanzania.

One limitation of our design was selection bias due to hospital-based enrolment. Patterns of delays among non-hospitalised febrile patients may differ from the patterns we identified in our study, and for this reason, our future work will include healthcare utilisation data from community members. There may have been additional selection bias from limiting our analysis to those participants who could be reached for follow-up. To assess this bias, we compared background characteristics between those lost to follow-up and those in the study cohort. The study cohort was more likely to report having health insurance, higher levels of education and at least one hospitalisation in the past 12 months. However, as one might expect delays to be more impactful among families with lower socioeconomic status, we speculate that our lost to follow-up bias would likely underestimate of the impact of delays, though we cannot conclusively infer the direction of bias. Also, while we used a robust matching process, this process introduced recall bias through participants' listing of severe symptoms. Our matching process also did not control for HIV seropositivity, as HIV status was self-reported and not laboratory confirmed. However, the prevalence of self-reported HIV seropositivity was balanced between cases and controls.

Our findings point to directions for future research and potential interventions. Future research may include characterising the determinants of the Three Delays that are associated with mortality, such as describing the explanatory models for illness among our patient population or studying the main areas of socioeconomic inequity in the community. Our results suggest interventions in our catchment area could include programmes to improve illness recognition in the community such as training community health workers ${ }^{42}{ }^{43}$ or teachers ${ }^{44}$ to recognise severe illness. Improved interfacility or community ambulances may help counter delays in transport. Our findings suggest at least two points of intervention to minimise health system delays. The first would be ensuring that all Tanzanian healthcare personnel 
at lower level healthcare facilities can recognise severe symptoms. The second would be strengthening referral pathways and developing explicit criteria for referral of severely ill febrile patients to tertiary care. Jointly these interventions may decrease mortality associated with febrile illness $>30 \%$ in adult and $>40 \%$ in paediatric patients who reach tertiary care during their illness.

In conclusion, we found that delays at home, in transport and in the healthcare system were associated with increased odds of death from febrile illness in northern Tanzania. Our social biopsy approach effectively measured the association between delays and mortality and could be applied in other settings to identify sociocultural, behavioural and health system factors that contribute to fatal outcomes from febrile illnesses.

\section{Author affiliations}

${ }^{1}$ Duke Global Health Institute, Duke University, Durham, North Carolina, USA ${ }^{2}$ Centre for International Health, University of Otago, Dunedin, New Zealand ${ }^{3}$ KCMC-Duke Collaboration, Kilimanjaro Christian Medical Centre, Moshi, Tanzania ${ }^{4}$ Perelman School of Medicine, University of Pennsylvania, Philadelphia, Pennsylvania, USA

${ }^{5}$ Kilimanjaro Christian Medical University College, Moshi, Tanzania

${ }^{6}$ Mawenzi Regional Referral Hospital, Moshi, Tanzania

${ }^{7}$ Arnold School of Public Health, University of South Carolina, Columbia, South Carolina, USA

${ }^{8}$ Division of Infectious Diseases, Duke University Medical Center, Durham, North Carolina, USA

Acknowledgements We would like to thank the study participants and their families as well as the clinical staff at Mawenzi Regional Referral Hospital and Kilimanjaro Christian Medical Center. We thank Francis P Karia, Frank M Kimaro, Tumsifu G Tarimo, Luig Mbuya and Edward Mshara for their administrative and logistical support. We would also like to thank Alphonce S Mushi and Robert Chuwa for data management and Elizabeth $\mathrm{L}$ Turner for guidance on statistical analysis.

Transparency declaration The guarantor affirms that this manuscript is an honest, accurate and transparent account of the study being reported. No important aspects of the study have been omitted. Any discrepancies from the study as planned have been explained.

Contributors Conceived and designed the study: MPR, JAC, JB and MJM. Performed the study: MJM, LN, FM, BTM, VPM, BFL, GFM and AGM. Analysed the data: MES, JO, CM, MJM and MPR. Wrote the manuscript: MES, MJM, CM, JB, BTM, VPM, JAC, JO and MPR. Sought and obtained funding: MPR, VPM, BTM and JAC. Guarantor: MES. All author contributions were made independently from any funding source.

Funding This study was supported by the US Health Resources and Services Administration through the Medical Education Partnership Initiative (T84HA21123), the US National Institutes of Allergy and Infectious Diseases through the Investigating Febrile Deaths in Tanzania (INDITe) grant (R01Al121378) and the Fogarty International Center through The Impact and Society Ecology of Bacterial Zoonoses in Northern Tanzania grant (R01TW009237). MPR received support from a National Institutes of Health Early Career Award (K23) grant (Al116869) and a Fogarty International Center Global Health Training Grant (R25TW009343). JB received support from Doris Duke International Clinical Research Fellowship. MJM received support from a University of Otago Frances G Cotter Scholarship.

Competing interests None declared.

Ethics approval This study was approved by the KCMC Research Ethics Committee, the Tanzania National Institute for Medical Research National Research Ethics Coordinating Committee and an institutional review board of Duke University Health System.

Provenance and peer review Not commissioned; externally peer reviewed.

Data sharing statement The full dataset and statistical code are available from the corresponding author at matthew.rubach@duke.edu. The presented data are anonymised, and risk of identification is low.
Open Access This is an Open Access article distributed in accordance with the Creative Commons Attribution Non Commercial (CC BY-NC 4.0) license, which permits others to distribute, remix, adapt, build upon this work non-commercially, and license their derivative works on different terms, provided the original work is properly cited and the use is non-commercial. See: http://creativecommons.org/ licenses/by-nc/4.0/

(c) Article author(s) (or their employer(s) unless otherwise stated in the text of the article) 2018. All rights reserved. No commercial use is permitted unless otherwise expressly granted.

\section{REFERENCES}

1. Prasad N, Sharples KJ, Murdoch DR, et al. Community prevalence of fever and relationship with malaria among infants and children in low-resource areas. Am J Trop Med Hyg 2015;93:178-80.

2. Crump JA, Morrissey AB, Nicholson WL, et al. Etiology of severe non-malaria febrile illness in Northern Tanzania: a prospective cohort study. PLoS Negl Trop Dis 2013;7:e2324.

3. Wang $\mathrm{H}$, Naghavi $\mathrm{M}$, Allen $\mathrm{C}$, et al. Global, regional, and national life expectancy, all-cause mortality, and cause-specific mortality for 249 causes of death, 1980-2015: a systematic analysis for the Global Burden of Disease Study 2015. Lancet 2016;388:1459-544.

4. Institute for Health Metrics and Evaluation (IHME). GBD Compare Data Visualization. Seattle, WA: IHME, University of Washington. http://vizhub.healthdata.org/gbd-compare

5. Jones G, Steketee RW, Black RE, et al. How many child deaths can we prevent this year? Lancet 2003;362:65-71.

6. Wilkinson RG, Marmot MG. Social Determinants of Health: The Solid Facts. 2nd ed: World Health Organization, 2003. http://www.euro. who.int/ data/assets/pdf file/0005/98438/e81384.pdf (accessed 4 Jan 2017).

7. Farmer P. Infections and Inequalities: The Modern Plagues: University of California Press, 2001.

8. Solar O, Irwin A. WHO Commision on Social Determinants of Health. A Conceptual Framework for Action on the Social Determinants of Health. 2007.

9. de Savigny D, Mayombana C, Mwageni E, et al. Care-seeking patterns for fatal malaria in Tanzania. Malar J 2004;3:27.

10. Hildenwall H, Tomson G, Kaija J, et al. "I never had the money for blood testing" - caretakers' experiences of care-seeking for fatal childhood fevers in rural Uganda - a mixed methods study. BMC Int Health Hum Rights 2008;8:12.

11. Källander K, Hildenwall $H$, Waiswa $P$, et al. Delayed care seeking for fatal pneumonia in children aged under five years in Uganda: a caseseries study. Bull World Health Organ 2008;86:332-8.

12. Källander K, Kadobera D, Williams TN, et al. Social autopsy: INDEPTH Network experiences of utility, process, practices, and challenges in investigating causes and contributors to mortality. Popul Health Metr 2011;9:44.

13. Kalter HD, Salgado R, Babille M, et al. Social autopsy for maternal and child deaths: a comprehensive literature review to examine the concept and the development of the method. Popul Health Metr 2011;9:45.

14. Bensaïd K, Yaroh AG, Kalter HD, et al. Verbal/Social Autopsy in Niger 2012-2013: A new tool for a better understanding of the neonatal and child mortality situation. J Glob Health 2016;6:10602.

15. Feikin DR, Audi A, Olack B, et al. Evaluation of the optimal recall period for disease symptoms in home-based morbidity surveillance in rural and urban Kenya. Int J Epidemiol 2010;39:450-8.

16. Zafar SN, Luby SP, Mendoza C. Recall errors in a weekly survey of diarrhoea in Guatemala: determining the optimal length of recall. Epidemiol Infect 2010;138:264-9.

17. Arnold BF, Ercumen A, Benjamin-Chung J, et al. Brief report. Epidemiology 2016;27:637-41.

18. World Health Organization Dept of Child and Adolescent Health and Development. Handbook: Integrated Management of Childhood IIIness (IMCI): World Health Organization, 2005.

19. World Health Organization Department of HIV. Integrated Management of Adolescent and Adult Illness: Interim Guidelines for First-Level Facility Health Workers at Health Centre and District Outpatient Clinic. WHO. 2005 http://www.who.int/hiv/pub/imai/en/ acutecarerev2_e.pdf

20. Thaddeus S, Maine D. Too far to walk: maternal mortality in context. Soc Sci Med 1994;38:1091-110.

21. Kang $\mathrm{Cl}$, Song JH, Ko KS, Ks K, et al. Clinical features and outcome of Staphylococcus aureus infection in elderly versus younger adult patients. Int J Infect Dis 2011;15:e58-62. 
22. Cooper GS, Shlaes DM, Salata RA. Intraabdominal infection: differences in presentation and outcome between younger patients and the elderly. Clin Infect Dis 1994;19:146-8.

23. Kaplan V, Angus DC, Griffin MF, et al. Hospitalized communityacquired pneumonia in the elderly: age- and sex-related patterns of care and outcome in the United States. Am J Respir Crit Care Med 2002;165:766-72.

24. Abadie A, Imbens GW. Large sample properties of matching estimators for average treatment effects. Econometrica 2006;74:235-67.

25. Abadie A, Imbens GW. Bias-corrected matching estimators for average treatment effects. J Bus Econ Stat 2011;29:1-11.

26. Austin PC. Balance diagnostics for comparing the distribution of baseline covariates between treatment groups in propensity-score matched samples. Stat Med 2009;28:3083-107.

27. Rosenbaum PR, Rubin DB. Constructing a Control Group Using Multivariate Matched Sampling Methods that Incorporate the Propensity Score. Am Stat 1985;39:33-8.

28. Normand ST, Landrum MB, Guadagnoli E, et al. Validating recommendations for coronary angiography following acute myocardial infarction in the elderly: a matched analysis using propensity scores. J Clin Epidemiol 2001;54:387-98.

29. Soundararajan K, Ho HK, Su B. Sankey diagram framework for energy and exergy flows. Appl Energy 2014;136:1035-42.

30. Schmidt M. The Sankey Diagram in Energy and Material Flow Management. J Ind Ecol 2008;12:82-94.

31. World Health Organization Country Office for Africa. Health Systems Profile: United Republic of Tanzania. 2004 http://www.afro.who.int/ index.php?option=com_docman\&task=doc_download\&gid=2839

32. Manzi F, Schellenberg JA, Hutton G, et al. Human resources for health care delivery in Tanzania: a multifaceted problem. Hum Resour Health 2012;10:3.

33. Mubyazi G, Kamugisha M, Mushi A, et al. Implications of decentralization for the control of tropical diseases in Tanzania: a case study of four districts. Int $J$ Health Plann Manage 2004;19(Suppl 1):S167-S185.

34. Hill Z, Kendall C, Arthur P, et al. Recognizing childhood illnesses and their traditional explanations: exploring options for care-seeking interventions in the context of the $\mathrm{IMCl}$ strategy in rural Ghana. Trop Med Int Health 2003;8:668-76.

35. Koffi AK, Libite PR, Moluh S, et al. Social autopsy study identifies determinants of neonatal mortality in Doume, Nguelemendouka and Abong-Mbang health districts, Eastern Region of Cameroon. J Glob Health 2015;5:10413.

36. Kalter HD, Yaroh AG, Maina A, et al. Verbal/social autopsy study helps explain the lack of decrease in neonatal mortality in Niger, 2007-2010. J Glob Health 2016;6:10604.

37. Koffi AK, Maina A, Yaroh AG, et al. Social determinants of child mortality in Niger: Results from the 2012 National Verbal and Social Autopsy Study. J Glob Health 2016;6:10603.

38. Mathew TP, Menown IB, McCarty D, et al. Impact of pre-hospital care in patients with acute myocardial infarction compared with those first managed in-hospital. Eur Heart $J$ 2003;24:161-71.

39. London JA, Mock CN, Quansah RE, et al. Priorities for improving hospital-based trauma care in an African city. J Trauma 2001:51:747-53.

40. Mock CN, Adzotor KE, Conklin E, et al. Trauma outcomes in the rural developing world: comparison with an urban level I trauma center. $J$ Trauma 1993;35:518-23.

41. Knight HE, Self A, Kennedy SH. Why are women dying when they reach hospital on time? A systematic review of the 'third delay'. PLoS One 2013;8:e63846.

42. Khanal S, Sharma J, GC VS, et al. Community health workers can identify and manage possible infections in neonates and young infants: MINI--a model from Nepal. J Health Popul Nutr 2011;29:255-64.

43. Lewin S, Munabi-Babigumira S, Glenton C, et al. Lay health workers in primary and community health care for maternal and child health and the management of infectious diseases. Lewin S, ed. Cochrane database of systematic reviews. 94. Chichester, UK: John Wiley \& Sons, Ltd, 2010.

44. Healthy Kids/Brighter Future. Healthy Kids/Brighter Future: Annual Report 2015-2016. 2016 http://media.wix.com/ugd/db99a5_0bc c399830a643189f6793bb983d9777.pdf (accessed 6 Apr 2017). 